\title{
Cognition-Based Rhetorical Appeals and the Teaching of English Composition
}

\author{
Jingwei ZHANG \\ School of Foreign Languages \\ Jilin Agricultural University \\ Changchun ,Jilin, 130118, China
}

\begin{abstract}
Nowadays, there is an increasing awareness of the upset situation concerning English writing among college English teachers. More and more teachers come to expose themselves to various but effective approaches to teaching writing in order to remedy the unsatisfying teaching situation. Process and product approaches are most commonly used in English writing teaching. However, these two approaches are observed to represent a reaction against each other. Teachers who favor the application of product approach to teach writing assume that students can produce good writing once they have mastered vocabulary and sentence of the language. But in such writing instruction, composing process skills are given relatively small role and to a certain degree students' motivation and interests remain undeveloped. But when applying process approach to teach writing, more and more teachers realize the disadvantages of this so-called "enabling" approach.For the purpose of finding an effective model of writing instruction for students this thesis is intended to provide an introductory rhetorical model from cognitive perspective for teaching writing.
\end{abstract}

KeywordsCognition, Conceptual Integration, Rhetorical Appeal, Writing

\section{INTRODUCTION}

With the development of technology and enhancement of communication, different parts of the world are more and more closely connected. English as an international language proves to be of great significance. English teaching and learning enjoy greater popularity as China has more opportunities to interact with foreign countries.

Among all the tasks of college English teaching, writing has long been recognized as one of the most boring and compelling tasks. It is a common phenomenon that teachers seem helpless with the students' poor writing ability while the students are always complaining about the dullness of the writing course.

Prompted and enlightened by the lectures on Rhetoric and Writing during my academic study, I pay attention to the abundant writing theories in the West, hoping they could provide illumination on the subject. I believe the application of these theories can make new sparks in the teaching of writing.

The general purpose of this study is to construct a rhetorical model which is supposed to serve as a generative model for the teaching of writing. It is hoped that my conception of writing embedded in the rhetorical model will solve some of the problems with the current methodology employed in the teaching of English writing. With a full awareness of the complexity and difficulty of the present study, we will try to adopt some methods appropriate for the research.

\section{THE ASSUMPTION OF COGNITIVE LINGUISTICS}

Cognitive linguistics claims that natural language is a product of the human mind, based on the same organizing principles that operate in other cognitive domain. Language, being at once both the creation of human cognition and an instrument in its service, is considered to stand a very good chance to reflect more general cognitive abilities in its structure and functioning. The view of language and meaning has received considerable support from some achievements in Cognitive Linguistics, particularly in Lakoff's research on conceptual metaphor and idealized cognitive models, Fillmore's frame semantics and construction grammar, Langacker and Talmy's cognitive and conceptual theories of grammar. It has some deep consequences for the very formulation of problem relative to meaning and form (Fauconnier, 1985: 2). Charles Fillmore's work on frame semantics, Terry Winograd's ideas about knowledge-representation systems, and George Lakoff's original conceptual of linguistic gestalts, which we have generalized to experiential gestalts in this study.

Although recent cognitive linguistics research is of great diversity with respect to the analytical tools used, the points emphasized, and perspectives adopted, there are some common views on language and cognition which lend coherences to this research and justify our talking about the cognitive paradigm.

\section{COMMUNICATION FROM COGNITIVE PERSPECTIVE}

According to the blending theory, the illustration of communication action process would be like this: during this process, it includes two inputs mental spaces: input 1 is the domain of speakers and input 2 is domain of audiences.

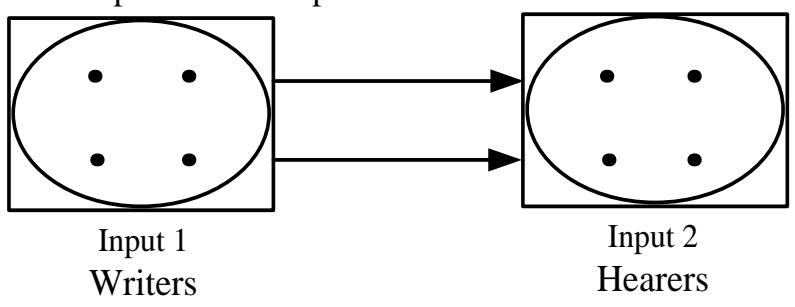

Fig. 1 Cross-Space Mapping

The message transmitted from input 1 to input 2; firstly composition of elements from the mental spaces of speakers 
(writers) and audiences (readers) to makes the sense of the message. Secondly, completion brings additional structure to the blend. Blends recruit a great range of background conceptual structure and knowledge, in which the message is judged. Thirdly, elaboration develops the blend through imaginative mental simulation according to principles and logic in the blend, the process in which the message is modified.

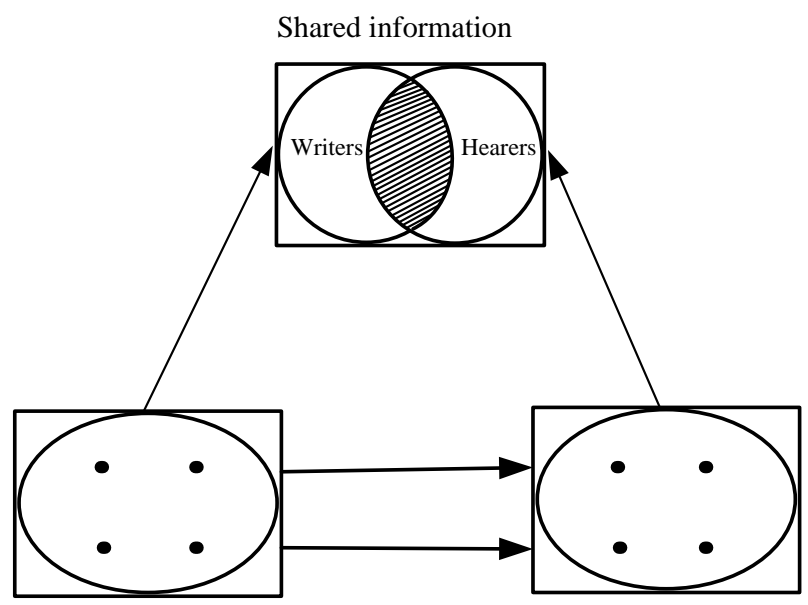

Input 1 Writers

Input 2 Hearers

Fig. 2 Shared information in Generic Space

Here is a well-known, highly visible example of conceptual blends for illustration of communication process:

Boat race

A modern catamaran is sailing from San Francisco to Boston in 1993, trying to go faster than a clipper that sailed the same course in 1853. A sailing magazine reports:

As we went to press, Rich Wilson and Bill Biewenga were barely maintaining a 4.5 day lead over the ghost of the clipper Northern Light, whose record run from San Francisco to Boston they're trying to beat. In 1853, the clipper made the passage in 76 days, 8 hours. - "Great America II," Latitude 38, volume 190, April1993, page 100.

There are two distinct events in this story, the run by the clipper in 1853 and the run by the catamaran in 1993 on (approximately) the same course. In the magazine quote, the two runs are merged into a single event, a race between the catamaran and the clipper's "ghost." The two distinct events correspond to two input mental spaces, which reflect salient aspects of each event: the voyage, the departure and arrival points, the period and time of travel, the boat, its positions at various times. The two events share a more schematic frame of sailing from San Francisco to Boston; this is a "generic" space, which connects them. Blending consists in partially matching the two inputs and projecting selectively from these two input spaces into a fourth mental space, the blended space: In the blended space, we have two boats on the same course that left the starting point, San Francisco, on the same day. Pattern completion allows us to construe this situation as a race (by importing the familiar background frame of racing and the emotions that go with it). This construal is emergent in the blend. The motion of the boats is structurally constrained by the mappings. Language signals the blend explicitly in this case by using the expression "ghost-ship." By "running the blend" imaginatively and dynamically — by unfolding the race through time - we have the relative positions of the boats and their dynamics.

\section{PERSUASION PROCESS FROM COGNITIVE PERSPECTIVE}

Although rhetoric is persuasive in nature, it is a kind of communication. The action still includes the process of message perception, understanding and modifying. Since it is the audience who makes the decision whether he has been persuaded or not, the conceptual blending process from audience's aspect should be like this (see figure3): first the input message from the speaker trigger the corresponding mental space in audience's long-term memory, then the audience will make the judgment on the mental space according to his own experiences, and at last, through imaginative mental simulation to modified the mental spaces, the audience makes the full sense and judgment of the message from the speaker. For example, David Ogilvy, one of the most influential advertisers in the field, designed a tabulate for Rolls-Royce in 1958. He used a unique sales motive, which can be analyzed by means of the following diagram:

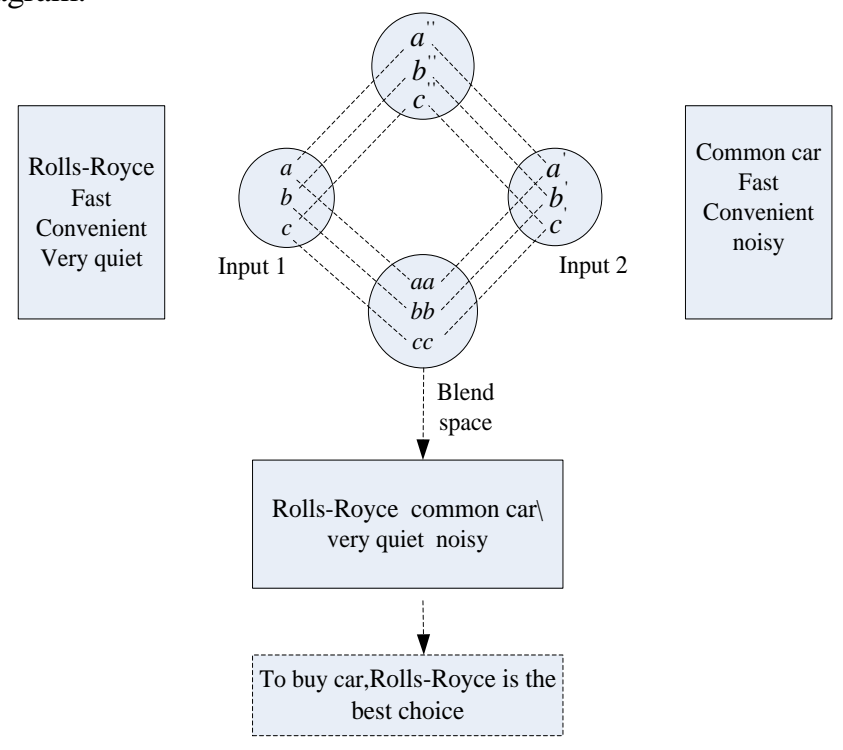

Fig. 3 Emergent Structure

"At 60 miles an hour the loudest noise in this new RollsRoyce comes from the electric clock."

In Rolls-Royce case, how does the audience realize the implied intention contained in such a sentence so as to convince them that Rolls-Royce is their best choice? Firstly, the message, like 60 miles an hour, loudest noise, new RollsRoyce etc., from input 1 trigger the audience's the image schema of the automobile in the long term memory of the audience in input 2, like Rolls-Royce is a brand of a type of cars, then all the related background information of automobile comes to the mind of audience to help him judge 
the information. Here, in this case the background information of automobile would be: cars are very fast and convenient, but too noisy, to chat or enjoy the music during driving is impossible unless the speed is less than perhaps 40 miles an hour for otherwise chatting will be like quarreling, and to hear the sound of electronic clock may only be possible when the car is stopped. At last, comparing with all the features with other cars, the audience will easily make the decision that, to by a car, Rolls-Royce is the best choice.

Another example is an ad for a steakhouse, which is a little bit complex:

If steak were a religion, this would be its cathedral.

Serving as a persuasion for food tasting, activating the desires of the food enthusiasts to come to the steakhouse, the ad realizes its implied intention to make the ad readers believe in the marvelous experience of eating steaks in Smith \& Wollensky. But how? The interpretation of this sentence involves first constructing the relationship steakhouse and cathedral. According to our common world knowledge, steakhouses and cathedrals do not share similarities between them. However, such a counterfactual scenario that sees both as equivalents is constructed in the blended space. In this case, the advertiser wants the audience to integrate some of their characteristics through imagination, thus making an inference that your experience in our steakhouse would be like your belief in God, so great and unforgettable. In the blend, some of the characteristics of religious beliefs are mapped onto the particular behavior of eating steaks. When the steakhouse is blended with the cathedral, the emergent meaning is constructed. It goes as follows: The framework of a steakhouse constructs Input 1, and the traditional framework of a cathedral constructs Input 2. In Input 1, we have such elements as steakhouse, customers, eating, steak, service. In Input 2, we have such elements as cathedral, believers or followers of a religion, religious activities (praying and singing), deeply rooted belief in God and persistent and voluntary activities. The solid lines represent cross-space mappings linking elements of cathedral and steakhouse. In the blended space, we construct the counterfactual scenario that food consumers in the steakhouse are having marvelous religious experiences. The organizing frame cathedral is projected to the blended space, and some unframed elements of the steakhouse are projected to the blended space from.

Once the blend is established, we can operate cognitively within that space, which allows us to manipulate two different things into a single scene. There is an emergent structure through composition: consumers come to the steakhouse to eat just as they come to do religious activities in the cathedral. Recruit background conceptual structures through completion: western people usually have deeplyrooted religious beliefs in God and are whole-heartedly devoted to the religion. Through elaboration process, we could infer the implied message that the advertiser intends to transform to us: after meal, you will have the same deeply rooted belief in our steak as your religious belief. A surprisingly marvelous taste! The entire analysis with conceptual integration network accurately shows the fundamental cognitive operation the consumers undergo in their mind.

\section{A COGNITION-BASED RHETORICAL MODEL}

As the previous illustration shows, from the cognitive perspective, the persuasion is a three-step process including composition, completion and elaboration. The names of each step clearly indicate their function. Firstly, the words trigger the experiences to compose image schema, then the schema will be enriched judged and valued by other background information, and at last the completed mental space will be chosen to be accept or not. So from cognitive perspective, persuasion is not a matter of choosing from a variety of texts the one that is the most persuasive, producing "Truth" by reasoning or testing the truthfulness of a conclusion. Therefore we may say that persuasion is a process in which the audience composes, judges and evaluates the mental space he constructed in his mind. So the gist of persuasion does not depend on what and how writer produces, but on what and how the audience constructs the input information in his mind.

To construct a more cogent or persuasive discourse is the aim of every writer, but "what kind of text or discourse is more persuasive" is a long-time asked question. Here are two jokes about marriage; are they persuasive?

a. Marriage gives you three rings:

engagement ring, wedding ring, and suffering.

b. Marriage is a bomb;

kills two!!!

We find that some people deeply identify with them, others are neutral, and still some people are laughing at them. To those who deeply identified with them, these two jokes are out of question persuasive. But their persuasiveness is reduced with the decrease of the degree of identification. So to different people the persuasiveness of the same discourse is different.

Through the cognitive analysis of persuasion process, we may find that what determined the result of persuasion is the new blending space in audience's mind, and what determined the new blending space in audience's mind is the conceptual integration process the mind undergoes. Hence instead of demonstration or formal logic, from cognitive perspective, to construct a persuasive discourse is a job of designing and controlling the conceptual integration process in audience's mind, and the writer should pay more attention to audience conceptual integration process so as to design the discourse correspondingly.

So, in the following section, we will keep a close watch on what happens during each integration process to see what we can do to control it.

Composition process, where a new rudimentary schema is foregrounded in the mind of the audience, is a process in which the audience perceives and understands the input information. Different from traditional truth-conditioned linguistics, cognitive linguistics believes that language is a trigger, without any real meaning, to stimulate a corresponding schema in the hearer's mind. Even the same word can stimulate different schemata in different people's 
minds because of their different embodied experiences. Hence in this process the writer should pay more attention to controlling the schema built in the mind of the audience by using a suitable trigger.

Completion is the second process in which the audience judges the reasonability of the newly built schema by his or her related background information. As it is often said, "man is the measure of the world." Each man makes the judgment according to his or her own personal experience. For example "dog" can mean friendly, but can also means heinous or dangerous, etc. to those who have been hurt by it, so what the writer in this step should do is try to control and lead the audience to make the judgment to the new schema.

It so often happened that the same information or news will be treated differently because of different news channels, or sometimes we will turn a deaf ears on a cleverest or soundest statement if the speaker's character is unfavorably considered. This is why the last step is crucial. Though it has been considered understandable and reasonable, the bad character of the writer can make all the previous efforts meaningless. So in the last step, to build a good image is important to a writer.

According to previous illustration, we may draw a diagram, which connect conceptual integration process and discourse construction process.

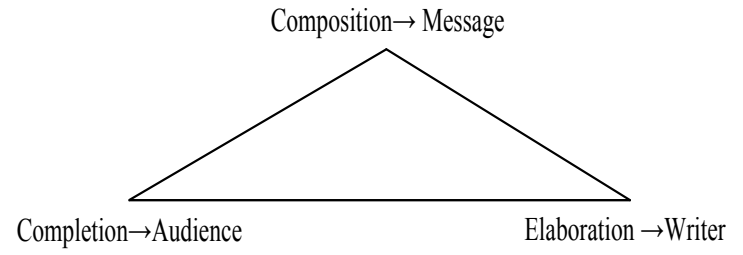

Fig. 4 Rhetorical Triangle 1

Composition $\rightarrow$ Message

Completion $\rightarrow$ Audience

Elaboration $\rightarrow$ Writer

So the rhetorical appeals should be considered through three aspects, namely, message aspect, audience aspect and writer's aspect. But in practical writing, the three often mingle together and influence each other. Hence based on the gist of traditional rhetorical theory, we try to make a persuasion model from cognitive perspective which can be easily applied in English writing. The model can be clearly shown by the Fig.5

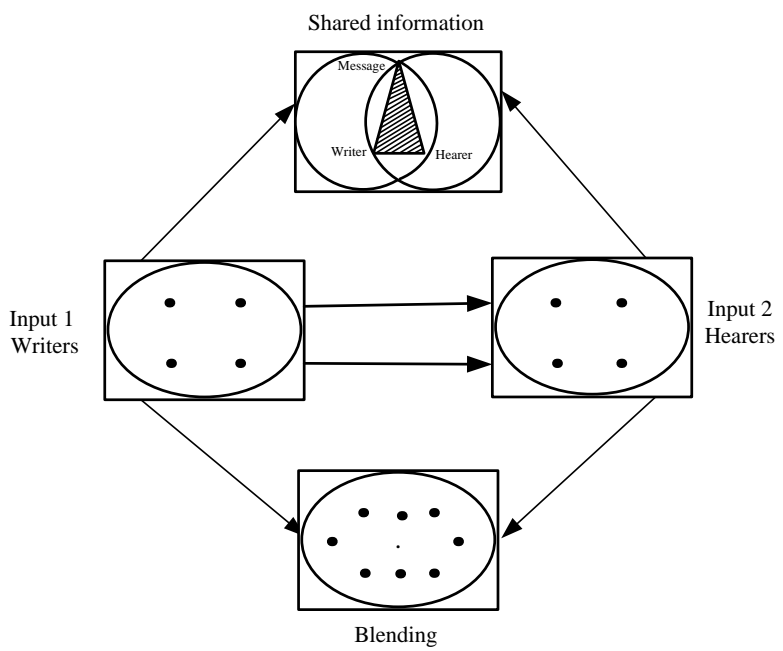

Fig. 5 Emergent Structure

The rhetorical triangle demonstrates a checklist of questions could be added to each of the appeals, which can help a writer plan, draft, and revise an argument. This could be shown clearly in the Fig.6.

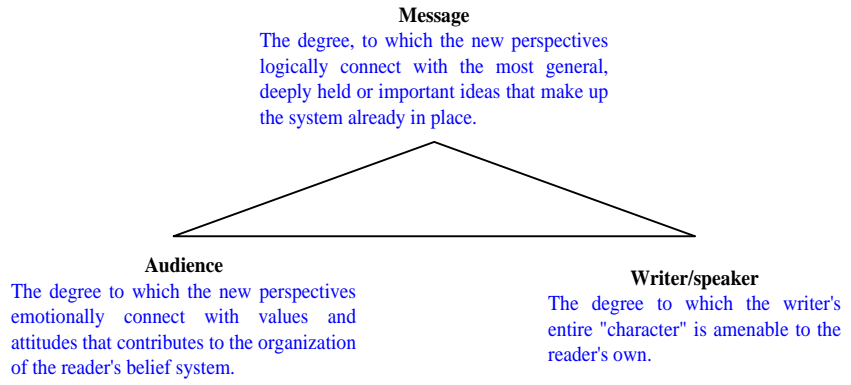

Fig. 6 Rhetorical Triangle 2

c. The triangle is essentially equilateral because the equal sides and angles illustrate the concept that each appeal is as important as the others. It also suggests that a balance of the three is important. Hence the degree of persuasiveness is related to the following three points:

- The degree, to which the new perspectives logically connect with the most general, deeply held or important ideas that make up the system already in place.

- The degree to which the new perspectives emotionally connect with values and attitudes that contributes to the organization of the reader's belief system.

- The degree to which the writer's entire "character" is amenable to the reader's own.

\section{A BRIEF SUMMARY OF THE STUDY}

The interest in the interrelationship between cognitive process and rhetoric in action inspires me on this study. As what Aristotle defined, "Rhetoric may be defined as the faculty of observing in any given cases the available means 
of persuasion." This is not a function of any other art. Every other art can instruct or persuade about its own particular subject-matter; for instance, medicine about what is healthy and unhealthy, geometry about the properties of magnitudes, arithmetic about numbers, and the same is true of the other arts and sciences. But rhetoric we look upon as the power of observing the means of persuasion on almost any subject presented to us; and that is why we say that, in its technical character, it is not concerned with any special or definite class of subjects."

\section{CONCLUSIONS}

Yet, up to now, there hasn't been any attempt to do rhetorical appeals from the perspective of conceptual integration perspective. This is one of the principal reasons for singling out the subject for discussion. We set out to provide an introduction to a relatively new approach to persuasion analysis. To find out the gist of persuasion and put them into practical use, so as to contribute to increasing the effectiveness of persuasion is our aim. And from the very beginning we set out to achieve our purpose of study step by step.

\section{Reference}

[1] Aristotle. Rhetoric. Trans. W. Rhys Roberts, New York: Random House, Inc., 1954.

[2] Bazerman, Charles. "A Relationship between Reading and Writing: The Conversational Model." College English, Vol. 41: 656-661,1980

[3] Benjamin Franklin. "Speech in the Constitutional Convention on the subject of salaries." June 2, 1787

[4] Berthoff, Ann E. The Making of Meaning: Metaphors, Models and Maxims for Writing Teachers. N.J.: Boynton/Cook, 1981.

[5] Black, Kathleen. "Audience Analysis and Persuasive Writing at the College Level" Research in the Teaching of English, vol. 23: 231-249, 1989

[6] Bliss,Ann. Rhetoric Structures for Multilingual and Multicultural Student. N.J. : Lawrence Erlbaum Associates, Inc. 2001.

[7] Booth, Wayne. "The Rhetoric of Fiction." College Composition and Communication. Vol.14 (1963): 139-45.

[8] Campbell, George. Philosophy of Rhetoric ed. Lloyd F. Bitzer. Carbondale: Southern Illinois University Press, 1963. 